\title{
En defensa de la identidad médica cubana
}

\author{
Defending the Cuban medical identity
}

\author{
Lic. Mabel Creagh Peña, Lic. Delfina González Serrano \\ Policlínico "Dr. Diego Tamayo". Habana Vieja. La Habana, Cuba.
}

\begin{abstract}
RESUMEN
Sobre el origen de los emblemas que tienen que ver con la medicina mucho se escribe pero poco se conoce, es por ello que aún se aprecia el uso incorrecto del Caduceo de Mercurio en instituciones de salud, y quizás por facilismo o por ignorancia se han adoptado símbolos que no son los que caracterizan a la medicina en Cuba. El propósito que persigue este trabajo es reflexionar sobre este tema por la necesidad del uso adecuado de los símbolos que identifican a los trabajadores de la salud pública cubana. Se revisaron artículos científicos y se exploraron sitios Web, por lo que se pudo demostrar que el emblema que identifica al sistema de salud cubano dignamente es el Caduceo de Esculapio, al que se le atribuyen dotes para calmar o apaciguar. Esta imagen del bastón con la serpiente es la que ha quedado como un atributo del dios curativo y ha llegado hasta la actualidad como símbolo de la medicina.
\end{abstract}

Palabras clave: Caduceo, símbolo de la medicina, mitología griega, Esculapio, Mercurio.

\begin{abstract}
Much has been written, but little is known about the origin of the symbols that have to do with medicine. This is the reason why we still notice the inadequate use of the caduceus of Mercury in health institutions, and the adoption of symbols that are not characteristic of medicine in Cuba. This paper was aimed at clarifying some concepts and pieces of information on this topic, which will allow properly using the symbols that should identify the Cuban health care workers. Several scientific articles were reviewed and a number of websites were visited to demonstrate that
\end{abstract}

http://scielo.sld.cu 
the identity symbol of the Cuban health system is the Rod of Asclepius, which is considered to have properties of calming down or pacifying people. The staff with the serpent entwined around it is the image which has remained as an attribute of the healer god and as a symbol of medicine at present.

Key words: Caduceus, symbol of medicine, Greek mythology, Asclepius, Mercury.

\section{INTRODUCCIÓN}

La palabra caduceo (vara con alas y serpientes entrelazadas), deriva del griego kadux que significa heraldo o embajador, y lo llevaban como señal de inviolabilidad personal (López Martín LG. Emblema de la medicina. Hosp. "William Soler". Cuba, 2007).

El nombre fue aplicado a una caña o vara divinatoria como insignia de autoridad, cualidad y oficio, emblema de la paz y la prosperidad, portaestandarte de todas las negociaciones, poder mediador entre los dioses y los hombres. ${ }^{1}$

Así los encontramos en las manos de Hermes-Mercurio, de Baco, Ceres, Venus, Hércules y otros, como símbolo de la felicidad, la paz y la concordia.

El caduceo ha sufrido numerosas transformaciones en sus motivos de composición a través de las edades de la humanidad, desde los tiempos de la prehistoria hasta la época actual y sobre todo, si tenemos presente las sabias y acertadas palabras del señor Legrand, al interpretar sus variaciones de forma y significado: "su forma ha sufrido el sello que le ha impreso el genio o carácter de los pueblos, su significado se ha perdido y ha sido aquel que sucesivamente le han atribuido los pueblos, que ignorantes del origen de estos símbolos, lo adoptaron y adaptaron a sus creencias y a sus costumbres."1

A nuestros días han llegado dos símbolos fundamentales, uno inspirado en Mercurio, astuto y frívolo, dios de comerciantes, viajeros y escritores, que entre sus atributos aparece como protector de la fecundidad; y el otro que se inspira en Esculapio, dios de la Medicina que dedicó su existencia física y mítica al tratamiento y curación de seres humanos. Cada uno evolucionó en la forma, en uno más acentuado que en el otro; pero ambos conservan su significación, al decir del profesor doctor Raimundo Castro y Bachiller (1902-1954), eminente profesor de Medicina Legal y Toxicología de la Universidad de La Habana y secretario de la Academia de Ciencias Médicas, Físicas y Naturales de La Habana, "...tenemos hoy como vemos dos caduceos, uno del comercio o tráfico entre las naciones y otro del ejercicio de la profesión médica o de las relaciones entre el médico y el paciente, que tuvieron su origen común". ${ }^{1}$

La Organización Mundial de la Salud (OMS) reconoce el Caduceo de Esculapio como emblema internacional de la Medicina ya que simboliza la dedicación hacia esta profesión y reivindica la imagen de la medicina asociada con el arte de curar a los enfermos. Hipócrates, al anunciar su famoso juramento pone a Esculapio por testigo junto a Apolo, Higea y Panacea, que se cumplirá la palabra empeñada hasta donde tenga poder y capacidad (López Martín LG. Emblema de la medicina. Hosp. "William Soler". Cuba, 2007). 
A la generación actual, y a las que sucederán, corresponde preservar el patrimonio cultural ganado mediante las luchas y victorias de nuestros antepasados, dar continuidad histórica a su obra y caracterizarse por la profundidad y seriedad en cada uno de sus actos, ya que entre los valores morales y la ética en el servicio de salud que se presta a la población debe estar presente la formación y la identidad cubana (Vidal Ledo M. El caduceo de la Medicina, símbolo distintivo y emblema oficial de la salud pública cubana. Ciudad de La Habana, Cuba, febrero de 2004). Por ello es oportuno refrescar algunos conceptos e información sobre este tema que nos permita reflexionar en la importancia del uso correcto de los símbolos que nos identifican como trabajadores de la salud pública cubana.

\section{RESEÑA HISTÓRICA}

Según la mitología griega, Mercurio, hijo del dios Zeus y de Maya, hizo una lira de un caparazón de tortuga y su música agradó tanto al dios Apolo que lo hizo el embajador de los dioses. Como especial servidor y correo de Zeus, Mercurio tenia un sombrero y sandalias aladas y llevaba un caduceo de oro o varita mágica, con serpientes enrolladas y alas en la parte superior. El bastón central era una vara para promover el entendimiento y las alas las llevaba para volar en sus quehaceres por órdenes de Apolo. Guiaba a las almas de los muertos hacia el submundo y se creía que tenía poderes mágicos sobre el sueño, y era responsable de la buena suerte y de la abundancia; pero a pesar de sus virtudes, este Dios era un peligroso enemigo, embaucador y ladrón.

En cierta ocasión separó Mercurio dos serpientes que estaban entrelazadas en mortal combate; desde entonces empezó a repartir mensajes entre enemigos y la varita se convirtió en símbolo de neutralidad convirtiéndose en el dios de los mercados, patrón del comercio y del juego de dados. Con su fascinadora elocuencia convencía a los que lo escuchaban que el mal era el bien.

El atributo de Hermes-Mercurio viene a ser el emblema por excelencia del comercio. Muy rudimentario al principio, ya que los artistas no reconocen las serpientes estilizadas de los fenicios, se convierte en un simple bastón sin ornamentos, donde la cabeza nudosa da nacimiento a dos ramas que bifurcándose se enroscan para aproximarse en sus extremidades, pero poco a poco y a medida que el arte progresa, reaparecen las dos serpientes, primero las cabezas y luego completas, a las cuales se les agregarán las dos alas en la parte superior de la vara de laurel o de olivo, ${ }^{1,2}$ característico de la época greco-romana, exactamente igual a como ha llegado a nuestra época (Fig.1).

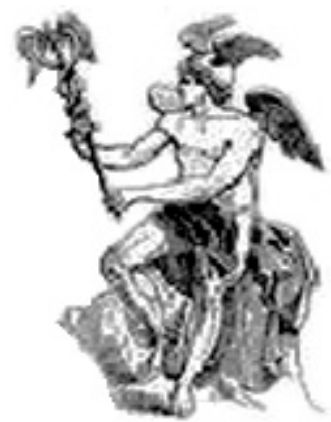

Fuente: ob. cit.1.

Fig. 1. El caduceo de Mercurio.

Al lado del Caduceo de Mercurio, evoluciona el otro, distinto en su imagen y en su significación: el Caduceo de Esculapio, el cual aparece en el siglo Ix, a.n.e. 
Esculapio, hijo del dios Apolo y de Corónide, aprendió todo lo que el centauro Quirón sabía del arte de la medicina y pronto se convirtió en un gran físico, su caduceo es un tronco o maza de cabeza nudosa donde se enrosca una serpiente que exterioriza la cabeza y queda separada y erguida. ${ }^{1} \mathrm{~A}$ Esculapio se le representa apoyado en su bastón que en sus orígenes era un simple palo que le servía de apoyo y devino en símbolo de autoridad y que se le atribuyen dotes para calmar o apaciguar; con la serpiente enroscada. La leyenda cuenta que mientras Esculapio en sus funciones de médico estaba atendiendo a Glaucus que estaba gravemente enfermo, ve a una serpiente que reptaba hacia su bastón, la mata y en ese momento otra serpiente se acercó a la que acababa de matar con unas hierbas en la boca que le devuelven la vida a la primera. De ese modo Esculapio conoce de las hierbas que resucitan a los muertos, ${ }^{1}$ y es por ello que la Serpiente ha sido considerada por la mayoría de las culturas de la humanidad como una divinidad, es temida y adorada en muchos mitos y leyendas por su veneno y por sus propiedades de mudar su piel, lo cual se interpreta como poder, virilidad, sabiduría, fertilidad, rejuvenecimiento, salud y prosperidad (Espino F. Caduceo medico. Un emblema mal empleado. Republica Dominicana, 2006). Esta imagen del bastón con la serpiente es la que ha seguido vigente como un atributo distintivo del dios curativo y ha llegado a nuestros días como símbolo de la medicina (Fig. 2). ${ }^{3-4}$

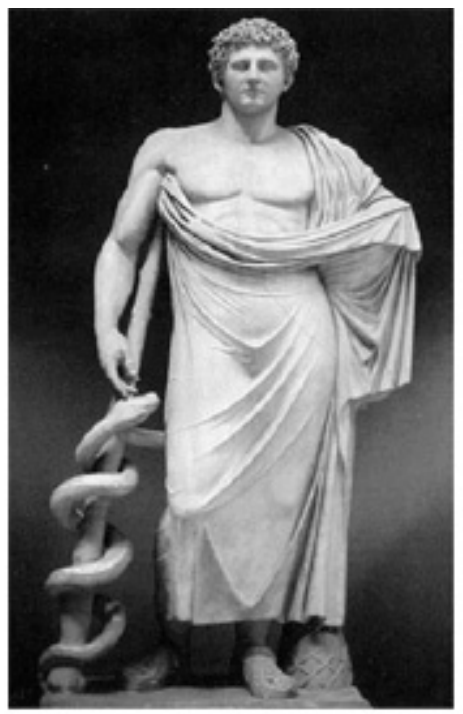

Fuente: Ob. cit. 1.

Fig. 2. El caduceo de Esculapio.

\section{Reflexiones a tener en cuenta}

El problema del caduceo radica en los valores que representa, he ahí donde surge el conflicto que va a las propias raíces de la práctica social. En aquellos lugares donde priman los principios mercantiles de cliente en vez de paciente, oferta en vez de atención médica, producto en vez de salud y la práctica de la medicina se ha convertido en un negocio, el símbolo del Caduceo de Mercurio, quizás transmita mejor el sentido mercantil que representa (Vidal Ledo M. El caduceo de la Medicina, símbolo distintivo y emblema oficial de la Salud Pública cubana. Ciudad de La Habana, Cuba, febrero de 2004), ya que recordemos que Mercurio es el dios de los viajeros, comerciantes, ladrones, oradores, escritores, protector de la fecundidad, y del trato social, mensajero entre los dioses, y hacedor de las conexiones entre el mundo y el inframundo. ${ }^{4}$ Quizás su utilización como emblema de las ciencias farmacéuticas sería correcto, dado que en las farmacias se expenden y comercializan los productos médicos para los pacientes, aunque, en el caso de Cuba 
en particular, esta acepción no es pertinente ya que el sistema de salud cubano subvenciona los medicamentos de manera que no constituya una carga económica para el enfermo y le resta importancia al asunto comercial que su adquisición entraña, por ello, la Asociación Farmacéutica Nacional tiene creado su propio caduceo. $^{5}$

Desde las luchas mambisas, transcurriendo por el período de la república, los profesionales de la salud cubana han cuidado que no se tergiverse el concepto de las Ciencias Médicas y Farmacéuticas. Raimundo Castro y Bachiller, constituyó la más alta expresión en la defensa de los emblemas basados en el ejercicio hipocrático de la medicina, que se corresponden con los símbolos de Esculapio, por ser Hipócrates su seguidor y concebir el ejercicio de esta profesión en el marco de la ética y moral rigurosas que la caracteriza. Le acompañaron en estas cruzadas, eminentes profesionales como el Diego Tamayo Figueredo, médico eminente y patriota, Arturo Sansores y García, médico forense y Arturo Sansores y López de Quintana, teniente coronel de la antigua Cruz Roja Cubana, ${ }^{6}$ entre otros, de lo cual dan fe sus numerosos testimonios y artículos en los que quedó esclarecido, según sus palabras que "era necesario ostentar un emblema, una insignia que dijera lo que éramos, médicos y cirujanos, [...] no comerciantes, profesión muy honorable, pero que no es la nuestra". Ello constituyó la señal para defender estos principios y quedó establecido, ratificado y oficializado en la Resolución Ministerial No. 64 del $2002,{ }^{7}$ como emblema de la Salud Pública Cubana, para su uso en todo el sistema de salud, el Caduceo de Esculapio, el cual termina en un pseudoespejo y la serpiente enroscada a todo lo largo, mirándose en él como símbolo de salud; el marco amarillo recuerda a Higea, hija de Esculapio, diosa de la salud, preservadora de la sabiduría y la higiene. Este bastón está rodeado por dos ramas de roble y laurel que trasmiten la fortaleza y la gloria que distingue a la actividad en la salud, a la izquierda, la de laurel con seis hojas y cuatro botones en flor, y a la derecha, una rama de roble con tres hojas y tres bellotas. ${ }^{1}$ Su representación garantiza la continuidad histórica en el sector de la salud de aquellos profesionales, que unida a la defensa de la Patria, también preservaban la identidad de la medicina cubana, de la cual somos herederos (Fig. 3).

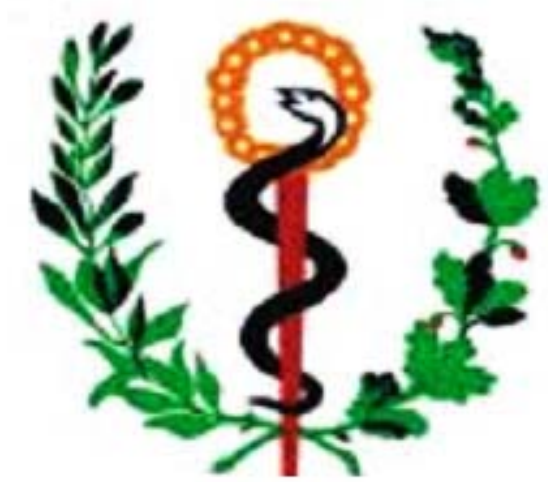

Fuente: Ob.cit. 1.

Fig. 3. El caduceo de la Medicina.

Las reflexiones que originan el análisis de este tema, permiten, no solo profundizar en la cultura y educación médica, sino, demostrar que se debe utilizar siempre el emblema de Esculapio, que es el que identifica la salud pública cubana, por su carácter humanista, valores éticos y morales. 
A toda la generación de profesionales cubanos y a las que los suceden corresponde preservar su patrimonio cultural, ganado a través de las luchas y victorias de sus antepasados y dar continuidad histórica a su obra, por lo que debe caracterizarles la profundidad y seriedad en cada uno de sus actos, ya que dentro de sus valores morales y ética en el servicio de salud que prestamos a nuestra población, debe estar presente nuestra formación y nuestra identidad cubana.

\section{REFERENCIAS BIBLIOGRÁFICAS}

1. de Castro Bachiller R. El Caduceo de la Medicina. Cuad Hist Salud Púb No.87 [Internet]. 2000[citado 16 Ene 2012]. Disponible en:

http://bvs.sld.cu/revistas/his/cua_87/cua0287.htm

2. Hermes. Microsoft® Student 2008 (DVD). Microsoft Corporation; 2007.

3. Asclepio. Microsoft® Student 2008 (DVD). Microsoft Corporation; 2007.

4. Rillo AG, Vega Mondragón L. Retorno al Caduceo de Esculapio [Internet]. [citado 14 May 2010]. Disponible en: http://www.naya.org.ar/congreso2002 Lponencias/arturo rillo.htm

5. Zayas-Bazán y Perdomo H. El Distintivo de la Asociación Farmacéutica Nacional. Cuad Hist Salud Púb No.87 [Internet]. 2000[citado 15 May 2010]. Disponible en: http://bvs.sld.cu/revistas/his/cua 87/cua0687.htm

6. Stenn F. El Caduceo y la Vara de Esculapio. Dos símbolos mitológicos vinculados con la Medicina, que derivan del culto a la serpiente. Cuad Hist Salud Púb No.87 [Internet]. 2000[citado 14 May 2010]. Disponible en:

http://bvs.sld.cu/revistas/his/cua 87/cua0487.htm

7. Gutiérrez LV, Mellado Pérez A. El símbolo de la medicina. Origen y evolución. Sagua La Grande, Villa Clara: Facultad de Ciencias Médicas; 2007.

Recibido: 27 de junio de 2011.

Aprobado: 30 de agosto de 2011.

Mabel Creagh Peña. Puerta Cerrada No. 11 e/ Suárez y Factoría. Habana Vieja. La Habana, Cuba. Teléf.: 8610005, 2082129.

Correo electrónico: mabel.creagh@infomed.sld.cu 